INVITED REVIEW

\title{
Innovative strategies for the treatment of thyroid cancer
}

\author{
Cornelia Schmutzler and Josef Koehrle \\ Medizinische Poliklinik, Abteilung Molekulare Innere Medizin und Klinische Forschergruppe, Universitaet Wuerzburg, Roentgenring 11, \\ D-97070 Wuerzburg, Germany \\ (Correspondence should be addressed to C Schmutzler; Email: C.Schmutzler@mail.uni-wuerzburg.de)
}

\begin{abstract}
Normally, thyroid cancer is a disease with a good prognosis, but about $30 \%$ of the tumours dedifferentiate and may finally develop into highly malignant anaplastic thyroid carcinomas with a mean survival time of less than 8 months. Due to the loss of thyroid-specific functions associated with dedifferentiation, these tumours are inaccessible to standard therapeutic procedures such as radioiodide therapy and thyroxine-mediated thyrotrophin suppression. Medullary thyroid carcinomas are also highly aggressive. Here, therapy is limited to surgery, and no alternative is left if patients do not respond to this standard procedure.

Obviously, new approaches would be desirable. Several novel approaches are currently being tested for the treatment of thyroid cancer. Many of them utilise methods of gene therapy, but follow different strategies: (1) reintroduction of the tumour suppressor p53 into a background lacking functional p53; (2) suicide gene therapy with ganciclovir and a transduced gene for herpes simplex virus thymidine kinase controlled by the thyroglobulin promoter; (3) strengthening of the antitumour immune response by expression of an adenovirus-delivered interleukin-2 (IL-2) gene; (4) induction of an immune response by DNA vaccination against the tumour marker calcitonin; (5) transduction of the thyroid sodium/iodide transporter gene to make tissues that do not accumulate iodide treatable by radioiodide therapy; (6) blocking of the expression of the oncogene c-myc by antisense oligonucleotides. While these approaches are still tested in vitro or in animal models, first results from pilot studies concerning other novel treatment modalities are available: (7) radioimmunotherapy exploits the carcinoembryonic antigen expressed on medullary thyroid carcinomas to target a radiolabelled antibody to the tumour; and (8) retinoic acid is used for a redifferentiation therapy in the case of thyroid cancer. Hopefully, one or the other of these novel strategies may probably extend after some time the current therapeutic repertoire for thyroid cancers and provide a perspective for otherwise untreatable patients.
\end{abstract}

European Journal of endocrinology 143 15-24

\section{Introduction}

Thyroid cancer, although the most frequent malignancy of the endocrine system, is a rare disease. It accounts for about $1 \%$ of all human cancers, with a higher prevalence in women ( 5 to 9 of 100000 ) as compared with men ( 2 to 4 of 100000 ). Usually, thyroid cancer is a well treatable disease with a good prognosis. Current therapeutic protocols include surgery to remove the thyroid gland in part or totally, followed, if necessary, by application of ${ }^{131}$ I. This radioisotope is accumulated in remnant or even disseminated thyrocytes by the thyroidal sodium/iodide symporter (NIS) and destroys them by internal radiation. Another widely used therapeutic measure is the administration of thyroxine $\left(\mathrm{T}_{4}\right)$ to suppress the production of the thyrotrophic growth factor TSH via hypothalamic and hypophyseal feedback; this aims to reduce the proliferation rate of residual thyroid tissue or metastases. In contrast, external radiation or chemotherapy, being less potent, are of minor importance (1).

These therapeutic measures are so far the only ones with proven efficiency and prognostic relevance. They are successfully applied for papillary (PTC) or follicular thyroid carcinomas (FTC), i.e. so-called well-differentiated thyroid carcinomas (DTC). However, in about 30\% of the cases, dedifferentiation of the cancers is observed (2). This is accompanied by a loss of thyroid-specific functions and properties, which, eventually, makes the tumours inaccessible to conventional therapy. Loss of iodide uptake, at least in part explained by the frequently observed reduction in the expression of the NIS (reviewed in ref. 3), makes radioiodide therapy infeasible. Also, dedifferentiated tumours lose the TSH receptor (TSHr) (4) and thus get insensitive to the growth-regulating effects of varying TSH levels; this 
obliterates any benefit from TSH suppression therapy by $\mathrm{T}_{4}$. It is telling in this context that presence of the TSHr usually correlates with a good prognosis for a thyroid neoplasm (5). Finally, extensive local tumour growth and/or distant metastases often preclude any further surgical intervention. When, after progressive dedifferentiation, the stage of anaplastic thyroid cancer (ATC) is attained, the prognosis is very bad. In fact, this carcinoma is the most malignant solid tumour in the human body, leading to death within a few months after diagnosis (6-8).

Medullary thyroid carcinomas (MTC), arising from the parafollicular, calcitonin-producing C-cells, make up about $3-5 \%$ of thyroid cancers. They also represent highly aggressive tumour types occurring in both sporadic $(\sim 80 \%)$ and familial forms $(\sim 20 \%)$. The therapeutic options for MTC are limited. Radiation and chemotherapy are of uncertain benefit so that surgery remains the only effective choice. However, after an operation, many patients exhibit elevated levels of calcitonin indicating the presence of a tumour not identifiable by imaging techniques, and eventually develop fatal disease. No alternative is left for the cases that are resistant to standard therapy $(1,9,10)$.

Obviously, there is a need for alternative therapeutic concepts. This review will summarise some recent publications on the development of novel strategies that after some time will probably extend the current therapeutic repertoire for thyroid cancers.

\section{Strategies and tools for gene therapy in the case of cancer}

Cancer is in essence a disease of genes (11). Genes encoding molecules crucially involved in the regulation of growth, differentiation and the maintenance of intact and functional tissues are lost, mutated or dysregulated. Both activation of growth-promoting genes, protooncogenes, and inactivation of growth-limiting genes, tumour suppressors, occurs. There is a hereditary component, contributing varying degrees of predisposition dependent on the type of cancer. The carcinogenic effect of retroviruses can be traced back to the fact that they integrate mutated copies of regulatory genes, which are insensitive to the normal control of gene expression, into the DNA of a host cell together with their own genome. Alternatively, by bringing their strong promoter and enhancer sequences next to a cellular gene they drive its overexpression. However, most cancer-related mutations are somatic, that means they accumulate in cells throughout the lifetime of an organism. Thereby environmental factors such as chemical carcinogens can display their influence. Altogether, it has been well established for some time, that in most instances, cancer is a multigenic disease and that more than one gene must be dysfunctional so that in the end malignant transformation and invasive growth will result. This is referred to as the 'multiple hit theory' of cancer (12).

The above-mentioned pathogenetic mechanisms, of course, also apply to thyroid cancer. Mutations of the RET oncogene play a prominent role in the pathogenesis of MTC, both in sporadic and in familial forms. It is advised that any patient with MTC should be genetically screened along with his or her relatives, and that family members carrying RET mutations should undergo preventive thyroid removal at early age (13). As for non-medullary thyroid cancers, they seem to arise via two different genetic pathways. FTC may develop from follicular adenomas; the identity of the underlying genetic alterations has not yet been completely clarified. Mutational activation of the RAS proto-oncogene has been observed, but in animal models this same alteration instead causes PTC (14). For PTC, it is estimated that about $3.5-6.2 \%$ of the patients have one or more first degree relatives also suffering from this cancer (15). Their precursor is the occult papillary microcarcinoma, and rearrangements of the TRK and RET proto-oncogenes are involved in the pathogenesis. DTC may develop into undifferentiated, anaplastic thyroid carcinomas. A characteristic of these highly malignant diseases are mutations of the tumour suppressor p53, which is found in up to $70 \%$ of the cases $(16,17)$.

On this background a lot of work is done to make cancer curable at the genetic level, namely by gene therapy (reviewed in 18, 19). In fact, most of the trials evaluating the potential of gene therapy do not deal with 'classical' hereditary diseases but with cancer. Several strategies have been tested, each of them devised for a certain range of purposes. A summary is given in Table 1; those techniques that have been used for thyroid cancer are emphasised and will be discussed below.

The cardinal point of gene therapy is the introduction of DNA into target cells. To date, there are two principal strategies to achieve this. Either the cells are manipulated ex vivo and afterwards reintroduced into the organism; thereby, only target cells receive the altered genes. Alternatively, the foreign DNA is directly applied, mostly by injecting it into the tumour tissue. As for the methods, there are several possibilities, which are summarised in Table 2. In general, viral vectors are most efficient. This holds true above all for retroviruses. Furthermore, they integrate their genome into that of the host whereby long-term gene expression results. However, for the same reason they may disturb the target cell's gene expression in an unforeseen and unwanted way. Another major disadvantage is that they only infect dividing cells. Adenoviruses, in contrast, do not integrate, but this implies that transduced genes are only temporarily active. Also, adenoviruses do not cause serious diseases, but they do trigger an immune response. Finally, they can be used to transduce non-dividing, differentiated cells. DNA transfection by the aid of lipid complexes is less efficient than 
Table 1 Strategies for gene therapy.

\begin{tabular}{|c|c|c|}
\hline Strategy & Intended effect & Example \\
\hline Oncogene silencing† & Shut-off of genes that support uncontrolled growth and formation of metastases & $c-m y c$ \\
\hline $\begin{array}{l}\text { Tumour suppressor } \\
\text { replacement† }\end{array}$ & Reintroduction of a wild-type copy of a lost or mutated gene that protects against cancer & p53 \\
\hline Prodrug therapy† & 'Suicide genes' render tumour cells sensitive against toxins applied as non-toxic prodrugs & TK/GCN \\
\hline Immunotherapy† & $\begin{array}{l}\text { Support of the organism's own defence mechanisms against cancer or triggering of immune } \\
\text { responses against tumour-specific antigens or tumour markers }\end{array}$ & IL-2 \\
\hline Genetic immunization† & $\begin{array}{l}\text { Generation of an immune response by introduction of 'naked' DNA coding for a cancer- } \\
\text { associated antigen }\end{array}$ & CEA \\
\hline Antisense therapy† & Sequence-specific oligonucleotides prevent synthesis of pathogenic proteins & c-myc \\
\hline Radioiodide therapy & $\begin{array}{l}\text { Expression of the NIS gene confers the ability to accumulate radioiodide to non-transporting } \\
\text { tissues }\end{array}$ & NIS \\
\hline Ribozyme therapy & Sequence-specific 'RNA enzymes' cleave mRNAs coding for pathogenic proteins & \\
\hline Antibody neutralisation & Introduction of intracellular (truncated) antibodies that neutralise pathogenic proteins & \\
\hline Chemoprotection & $\begin{array}{l}\text { Introduction of genes coding for proteins that protect normal cells from effects of high-dose } \\
\text { chemotherapy }\end{array}$ & \\
\hline
\end{tabular}

†Strategies tested for the treatment of thyroid cancer.

the virus-based methods but has neither of their disadvantages. This technique may be used for $e x$ vivo manipulation as the altered cells can be expanded after transduction, thus compensating for the low efficiency. Liposome-mediated DNA transfection is a widely applied method for pilot experiments in vitro using cell culture model systems. Finally, even 'naked' DNA in the absence of any vehicle may be used for vaccination against tumour-associated genes (20-22).

\section{Gene therapy for thyroid cancer}

\section{Tumour suppressor replacement: p53}

Much work has been done on p53 (23), a protein that acts, under normal conditions, as a tumour suppressor. It is a transcription factor which surveys the integrity of the genome. If genomic DNA is mutated, for example by ionising radiation, chemotherapeutic drugs or hypoxia, p53 arrests the cell cycle to allow for repair. If damage is too severe and DNA alterations are not likely to be completely removed, p53 induces apoptosis to eradicate cells with genomic alterations and to prevent their propagation.

p53 is the most frequently affected protein in human neoplasms, being altered in $40-45 \%$ of the tumours. Usually, one allele is deleted and the other one is mutated and dysfunctional, which contributes to tumour progression towards increasing malignancy and reduced differentiation. This also seems to apply for thyroid cancer. p53 is intact in the healthy thyroid, in benign thyroid disease or in differentiated carcinomas, but there is a high prevalence of p53 mutations in dedifferentiated carcinomas correlating with the most aggressive histologic tumour types. Thus, as already mentioned, p53 mutations seem to be a late event in thyroid carcinomas $(24,25)$.

The central role of $\mathrm{p} 53$ for the pathogenesis of thyroid cancer has made it a potential target for gene therapy. In a couple of studies using thyroid carcinoma cell lines with p53 mutations it has been shown that reintroduction of wild-type p53 causes a more differentiated

Table 2 Vehicles for gene therapy.

\begin{tabular}{|c|c|c|}
\hline Vehicle & Advantages & Disadvantages \\
\hline Retroviruses & High efficiency; long-term expression of transfected genes & $\begin{array}{l}\text { Insert into host cell's DNA and may disturb } \\
\text { gene expression; do not infect } \\
\text { non-dividing cells }\end{array}$ \\
\hline Adenoviruses & $\begin{array}{l}\text { Do not cause serious diseases; high capacity for uptake } \\
\text { of foreign DNA; do not integrate into host DNA; also infect } \\
\text { non-dividing cells }\end{array}$ & $\begin{array}{l}\text { Inserted genes temporarily active only; } \\
\text { cause immune response }\end{array}$ \\
\hline Adeno-associated viruses & $\begin{array}{l}\text { Long-term expression of transfected genes; do not cause } \\
\text { serious diseases }\end{array}$ & $\begin{array}{l}\text { Insert into host cell's DNA and may disturb } \\
\text { gene expression; low capacity for uptake } \\
\text { of foreign DNA }\end{array}$ \\
\hline Liposomes & Do not cause diseases or immune response & $\begin{array}{l}\text { Gene transfer less efficient than with viral } \\
\text { vectors }\end{array}$ \\
\hline 'Naked’ DNA & $\begin{array}{l}\text { Applicable for vaccination; does not cause diseases or } \\
\text { immune responses }\end{array}$ & $\begin{array}{l}\text { Gene transfer inefficient; unstable in } \\
\text { most tissues }\end{array}$ \\
\hline
\end{tabular}


phenotype of the cells. Expression of the thyroid-specific differentiation markers thyroperoxidase (TPO), thyroglobulin (Tg), and TSHr, of the thyroid-specific transcription factor Pax8, and of MHC class II antigens is stimulated. Furthermore, responsivity to the physiological stimulator TSH is restored and the tumourigenic potential is decreased. Proliferation is inhibited, both in thyrocyte and C-cell derived tumour lines; however, not apoptosis but cell-cycle arrest seems to be the cause $(26-30)$.

According to what is known on the function of $\mathrm{p} 53$, its re-expression in a p53-deficient tumour might enhance the tumour's sensitivity to radiation or chemotherapy. This has been tested in two recent papers. Narimatsu et al. (31) stably transfected the p53null anaplastic thyroid carcinoma cell line FRO with a temperature-sensitive mutant of the wild-type p53 gene. They did not detect a sensitising effect against the three chemotherapeuticals cisplatin, 5-fluorocytosin and doxorubicin. However, they did observe a sensitisation against ionising radiation under the permissive temperature of $32^{\circ} \mathrm{C}$ compared with $37^{\circ} \mathrm{C}$; cell viability was decreased by a factor of $\sim 2$ at $7.5 \mathrm{~Gy}$ and by a factor of $\sim 3.5$ at $10 \mathrm{~Gy}$ of $\gamma$-irradiation. Blagosklonny et al. (32) transduced the three anaplastic thyroid carcinoma cell lines BHT-101, SW-1736 and KAT-4, which express mutant p53, with an adenovirus coding for wild-type p53. This induced the p53responsive proteins p21 and $\mathrm{Mdm}-2$ as well as a cytotoxic effect. Furthermore, the cell lines became more sensitive to adriamycin with an about tenfold increase in $\mathrm{IC}_{50}$ values. However, this approach has so far only been tested in vitro, and further studies are needed to show whether it is efficient in experimental animals or, finally, in patients as it is already done in the case of other epithelial tumours (23).

\section{Suicide gene therapy}

In this approach, gene transfer is used to introduce into the tumour a vector coding for a 'sensitising enzyme' (33). A chemotherapeutic agent is then applied as a non-toxic prodrug, which is activated only in those cells that express the sensitising enzyme. A positive concomitant is that more cells are killed than have actually been transduced, because the activated drug is secreted and acts on neighbouring cells, too. This is the so-called 'bystander effect'. The most widely used system for suicide therapy is the prodrug ganciclovir (GCN) together with herpes simplex virus type 1 thymidine kinase (HSV1-TK) (33). GCN is a nucleotide analogue, and HSV1-TK, in contrast to normal mammalian TK, preferentially phosphorylates GCN. Monophosphorylated GCN is then converted to its triphosphate by cellular kinases and interferes with cell propagation by competition with normal nucleotides during replication. Growing cells will be destroyed preferentially, which limits the side effects on normal tissue. Therefore, this technique has above all been tested for brain cancer. Here, minimal damage of brain function is expected as healthy neurones have stopped proliferation and will not be affected. As the thyroid gland is a very slowly growing tissue, gene therapy using GCN and the TK gene might be a method of choice also in this case. Several other prodrug/sensitising enzyme systems have also been tested for thyroid cancer (34).

Nishihara et al. (35) transduced WRO and FRO thyroid carcinoma cells with the HSV1-TK gene under the control of the cytomegalovirus promoter using a retroviral vector. They observed a dose- and timedependent decrease of living cells after GCN treatment accompanied by increased apoptosis. A bystander effect was also observed. Low doses of GCN, which produced only minor cytotoxicity by themselves, resulted in a sensitisation against ionising radiation. Growth inhibition, bystander effect and radiosensitisation were also demonstrated in tumours generated by xenotransplantation of TK-transduced FRO cells to nude mice.

To minimise effects on other organs, the activity of the transduced sensitising enzyme should be limited to the target tissues. This might be achieved by intratumoural injection, but such a strategy would exclude disseminated diffuse metastases from the cytotoxic effect. Braiden et al. (36) used a recombinant retrovirus carrying TK under the control of the $\mathrm{Tg}$ promoter. With this vector, they transduced the differentiated rat thyrocyte line FRTL-5, the FRTL-5-derived malignant cell line FRTC, and the human anaplastic thyroid carcinoma cell line FRO. They detected a $13000-$ and a 160-fold increase in the sensitivity to GCN in the presence and a $\sim 4$ - and $\sim 27$-fold increase in the absence of TSH in FRTL-5 and FRTC cells respectively. These two cell lines also expressed Tg. However, in the case of the Tg-negative line FRO, there was no difference between parental and transduced cells. TK expression under the control of a foreign promoter is less efficient than under a strong viral promoter. Nagayama et al. (37), by exploiting the Cre-loxP system were able to enhance the activity of the Tg promoter. They constructed recombinant adenoviruses with the HSV1-TK gene under the control of the strong cytomegalovirus promoter, but separated by a stuffer fragment, and with the Cre recombinase gene under the control of the $\mathrm{Tg}$ promoter. Thereby, Cre activated HSV1-TK gene transcription only in thyroid cell lines expressing Tg (FRTL-5 and FRTC). This resulted in a five- to tenfold higher in vitro cytotoxic effect of TK/GCN than with a recombinant adenovirus with the HSV1-TK gene itself fused to the Tg promoter. Enhanced inhibition of tumour growth in vivo using FRTC cells xenotransplanted s.c. was also observed in the case of the combined Tg/Cre-loxP system. However, tumour regression was not observed. Obviously, such an approach is limited to those cancers that still maintain Tg expression, which seems to apply for a great part of thyroid carcinomas as $\mathrm{Tg}$ is used as a sensitive tumour marker also in advanced stages. 
However, one must bear in mind that dedifferentiation is known to coincide with a decreased expression of thyroid-specific transcription factors (reviewed in ref. 38). This will then reduce the efficiency of $\mathrm{Tg}$ expression and of any transgene controlled by the $\mathrm{Tg}$ promoter.

\section{Immunotherapy: interleukin-2}

Although tumours express antigens that may trigger an antitumour immune response, they often evade the surveillance of the immune system. Expression of class I and II MHC antigens may be disturbed, so that neither presentation of processed antigens nor proper T-cell activation occurs. Also, the immune response may be suppressed by products of the tumour or immune tolerance against tumour antigens may develop. Applying immunostimulatory agents to enhance defence reactions by the host should be a promising strategy against cancer. A candidate in this context is the T-cell growth factor interleukin-2 (IL-2). It stimulates proliferation and differentiation of $\mathrm{NK}, \mathrm{CD}^{+}$and CTL effector cells and thereby regulates both specific and non-specific immune responses. Systemic administration of IL-2 produced an antitumoural immunity in animal models. However, the doses required to achieve a therapeutical effect in patients usually cause severe side effects so that this approach is of limited benefit. Local, intratumoural application of the cytokine could provide far higher concentrations and thus circumvent this problem. Alternatively, the IL-2 gene may be introduced into the tumour, an approach that has been tested in animal models for several types of cancers. First results in patients were somewhat disappointing and recent protocols switch to the transduction of combinations of cytokine genes instead of one gene (39).

In three papers by Zhang et al. (40-42) the feasibility of this approach in the case of MTC was investigated. They used a replication defective adenovirus to transduce MTC cell lines with the murine IL-2 (mIL-2) gene under the control of the human cytomegalovirus promoter, which established two cell lines (murine and human MTC cells) that secreted large amounts of mIL-2. When the murine cells were injected into syngeneic $\mathrm{BALB} / \mathrm{c}$ mice, a markedly impaired tumour growth was observed for the mIL-2-positive cells. In two of ten animals growth of the xenografts was detectable after 26 days whereas in the case of mock-transfected and parental mMTC cells nine of ten and ten of ten animals had developed tumours. Similar effects were obtained in immunodeficient BALB/c-SCID mice. This observation together with cytotoxicity assays indicated that both specific and unspecific antitumour activities were involved. Reinjection of the parental cells into tumourfree animals after 60 days did not produce tumours, revealing a long-term immunity against mMTC cells. If the IL-2-encoding adenovirus was injected directly into previously generated tumours, regression was observed in $69 \%$ of 'small' tumours $\left(<30 \mathrm{~mm}^{3}\right)$ and stabilisation in the case of 'large' tumours $\left(>30 \mathrm{~mm}^{3}\right)$; again, longterm immunity was observed as well as a massive infiltration of $\mathrm{CD}^{+}$and $\mathrm{CD}^{+}$cells in IL-2 treated tumours. Using a rat model, similar results were obtained. To evaluate the safety of the procedure, adenovirus was also administered i.v. to monitor effects on other tissues. Dissemination to the liver was observed, along with mild to extensive lymphocyte infiltration to the sinusoids and triads of the liver, but this did not affect GPT and GOT enzyme levels. Two of 12 animals showed signs of cell necrosis in the spleen, but there were no specific changes in the lung and the kidneys. Altogether it was concluded from this data that the adenoviral vector used to transduce mIL-2 was safe for gene therapy.

\section{Gene therapy using the sodium/iodide-symporter}

Cloning of the rat and, shortly afterwards, the human sodium/iodide symporter (rNIS and hNIS, respectively) resulted in a substantial insight into the pathogenesis of thyroid diseases including thyroid cancer. As mentioned above, reduced expression or functionality of this molecule may contribute to the failure of radioiodide therapy due to a lack of iodide accumulation in advanced thyroid carcinomas (3). Shimura et al. (43) investigated whether reexpression of this transporter molecule after gene transfer leads to a reinduction of iodide transport in non-accumulating thyroid carcinoma cell lines. They stably transfected rat FRT-Tc cells with rNIS and transplanted them s.c. to Fisher rats. The resulting tumours concentrated radioiodide 27-fold up to a dose of $4 \mathrm{~Gy}$ per $\mathrm{mCi}{ }^{131} \mathrm{I}$. However, there was no growth inhibitory effect after radioiodide treatment as the tumour volume had not changed 2 or 3 weeks post therapy.

Two other publications also focus on the NIS, albeit not in the context of thyroid cancer. They exemplify that this molecule may be useful in the future not only for treating thyroid cancer but many other cancers by radioiodide, too. NIS belongs to a large and widely expressed class of sodium-dependent solute transporters termed after its prototype, a sodium/glucose symporter, the SGLT1 family (44). As NIS shares structural and functional similarity with these molecules, it is no surprise that it should find the prerequisites required for its activity in a great variety of cell types, although its own expression is limited in range (reviewed in ref. 45). This has prompted efforts to express the NIS in cells originating from tissues other than the thyroid, which normally do not transport iodide, to make them amenable to radioiodide therapy. Mandell et al. (46) transfected rNIS by the use of retroviruses into human melanoma, hepatocarcinoma, colon carcinoma and ovarian adenocarcinoma cell lines. The cells then accumulated iodide, either in cell culture or in tumours that were generated by xenotransplantation into nude 
mice. In an in vitro clonogenic assay, they showed that rNIS-transfected cells were selectively killed by radioiodide, although they did not address the question whether there is also a radioiodide-induced growth reduction in the xenografts. Spitzweg et al. (47) used a construct with the NIS gene under the control of the androgen-responsive promoter of the prostate specific antigen (PSA) for transient as well as stable transfection experiments. Expression of the NIS protein in transfected cells was demonstrated by Western blot. Radioiodide uptake was androgen responsive, but only in such cells that also express PSA.

It should be added that a recent report suggests that the loss of radioiodide uptake in thyroid carcinomas could be due to reduced transcription caused by an aberrant methylation of the NIS gene (48). Tumour samples did not reveal a specific methylation pattern in correlation with a deficiency in NIS mRNA. However, treatment of seven thyroid carcinoma cells lines lacking NIS mRNA with 5-azacytidine or sodium butyrate restored hNIS mRNA expression in four and iodide uptake in two of them. This was concomitant with demethylation of the NIS gene in the untranslated region of the first exon. Thus, NIS expression and, as a consequence, NIS activity may be restored by manipulating DNA methylation at least in a subset of thyroid carcinomas.

\section{Genetic immunisation: calcitonin}

Immune responses can be triggered by simple injection of naked plasmid DNA coding for an antigen (49). In MTC, the tumour marker calcitonin may represent a target for immunotherapy as it is highly specific for $\mathrm{C}$ cells and tumours derived therefrom and most tumours express this molecule. Haupt et al. (50) developed a DNA vaccine plasmid encoding preprocalcitonin under the control of the cytomegalovirus promoter. This construct was used to coat gold particles and intradermally injected by the gene gun. An antibody response was detected in four and a significant T-cell proliferation was detected in two out of five animals. Coinjection of granulocyte macrophage colony stimulating factor enhanced the specific immune response.

\section{Antisense therapy}

The c-myc proto-oncogene codes for a nuclear protein that acts as a transcription factor transducing mitogenic stimuli. The gene is amplified and constitutively active in a couple of tumours (11). In thyroid cancer, overexpression of c-myc seems to be related to an unfavourable prognosis. In the thyroid gland, c-myc is involved in the growth regulation via the cAMP pathway (51). Cerutti et al. (52) found an increase in c-myc mRNA expression in seven human thyroid carcinoma cell lines as compared with normal thyroid primary cells, with the highest levels in the most malignant cell lines ARO and FRO. They also examined 50 thyroid tumour samples and detected elevated c-myc mRNA levels in 4 of 24 PTC, in one of eight FTC, and in five of six ATC. Blocking c-myc protein expression with antisense oligonucleotides against the translation initiation region of the mRNA significantly reduced the growth rate of the thyroid carcinoma cell lines. Although these experiments were primarily done to clarify the biological role of c-myc in transformation of thyrocytes, they may also have relevance for gene therapy of thyroid cancer.

\section{Other novel approaches for the treatment of thyroid cancer}

\section{Radioimmunotherapy}

Carcinoembryonic antigen (CEA) is a tumour-associated antigen which occurs among a wide range of cancers, among them MTC. Mouse monoclonal anti-CEA antibodies are available that can be used in their radioiodinated form for radioimmunotherapy. Juweid et al. (53) initiated a Phase I/II study to determine the safety, maximum tolerated dose (MTD), and therapeutic potential of radioisotope-labelled ${ }^{131} \mathrm{I}-\mathrm{MN}-14 \mathrm{~F}(\mathrm{ab}) 2$ anti-CEA MAb for patients with metastatic MTC. Radioantibody doses of 140, 180 and 220 Gy to the bone marrow were applied to 3, 11 and 1 patient, respectively. This resulted in a mean tumour dose of $23.7 \pm 27.5 \mathrm{cGy} / \mathrm{mCi}$ (range $1.3-124 \mathrm{cGy} / \mathrm{mCi}$; median $16.6 \mathrm{cGy} / \mathrm{mCi}$ ), which was 37.7-fold higher than the whole body dose. Myelosuppression was detected as the only treatment-related dose limiting toxicity, and the maximal tolerated dose appeared to be $180 \mathrm{~Gy}$ to the bone marrow. In seven patients, a 55\% median reduction in the tumour marker calcitonin was detected at a median time of 3 months after therapy. In one patient, a $45 \%$ reduction of the tumour burden in the neck region was observed. The disease was radiologically stable for 3-26 months in 11 of 12 assessable patients. The therapy was well tolerated and showed evidence of biochemical and radiological antitumour activity. However, after 2-6 weeks, antimouse antibodies had developed in 8 of the 15 patients, so that the use of humanised antibodies for future radioimmunotherapy was recommended.

\section{Retinoic acid redifferentiation therapy}

Another novel anticancer strategy - at least in the context of the thyroid gland - may exploit the growth-inhibiting and differentiation-inducing properties of retinoic acids. These are the biologically active metabolites of vitamin $A$, and their effects in the organisms of vertebrates range from early embryonic differentiation over limb morphogenesis to the maintenance of functional tissues in the adult (54-60). The paradigm of retinoic acid (RA) therapy is acute promyelocytic leukaemia, where up to $90 \%$ remission can be achieved (61). However, 
retinoids have also been used for therapy and chemoprevention in the case of many other cancer entities (62). As for thyroid cells, several in vitro studies indicated that retinoids may indeed have effects. Components relevant for growth, thyroid-specific functions and metastatic potential of thyrocytes are influenced by RA in a way that can be interpreted as a partial redifferentiation. Examples are type I $5^{\prime}$ deiodinase (63, $64)$, NIS mRNA and iodide uptake $(65,66)$, ICAM-1 (67), and CD97 (68).

These data, above all those on the NIS and on iodide uptake, make it probable that thyroid tumours may be redifferentiated at least to such a degree that established treatment protocols, especially radioiodide therapy, may be applicable again. They have prompted a multicentric clinical study to test the potential of retinoids for a redifferentiation therapy of thyroid cancer. So far, 75 patients with poorly differentiated, inoperable thyroid cancer and absent or insufficient iodide uptake have been included $(69,70)$. They were treated with oral doses of 1.0-1.5 mg 13-cis-RA per kg body weight and day. Monitoring was performed by imaging (CT, MR, PET), radioscintigraphy (therapeutic doses of 3-10 $\mathrm{GBq}$ ), and determination of the tumour marker Tg. Side effects were usually well tolerated; only in one case the treatment had to be stopped due to an increase in liver enzymes. Fifty-six of the patients could be evaluated. Of 54 patients, $11(20 \%)$ showed a decrease and 18 (33\%) a stable level of Tg during follow-up. Radioiodide uptake increased in 21 of 52 patients (40\%), F-18-fluorodeoxyglucose uptake decreased in six and remained unchanged in 25 of 32 patients (19 and 78\% respectively). In 4 (11\%) of 36 patients, tumour size regressed, and in 11 (31\%) no further growth was detectable. In another study comprising 12 patients, Grünwald et al. $(71,72)$ reported comparable results.

To explore more precisely whether there was an actual therapeutic benefit, out of the 75 patients a subgroup of 20 patients with well documented and comparable courses of disease was selected for a closer analysis. Here, Tg was monitored at least once before and after RA treatment under stimulating conditions $\left(\mathrm{T}_{4}\right.$ withdrawal; $\left.\mathrm{TSH}>30 \mu \mathrm{U} / \mathrm{ml}\right)$ and a radioiodide scan as well as data on tumour size (CT, MR) had to be available. Using these categories the patients were assigned by three independent examiners to three groups: responders, where either radioiodide uptake and at least one other parameter had improved; stable disease, where radioiodide uptake might have improved but no change of any other parameter was observed; and non-responders, where no effect on radioiodide uptake was observed and either tumour size or Tg levels were progressive. There were four responders, four patients with stable disease, and 11 non-responders; one patient could not be classified. This means that $20 \%$ of the patients showed an improvement, and another $20 \%$ at least did not experience a further progression of their disease. Follow-up was from 3 to 35 months. In evaluating these data it should be noted that all the patients had a history of year-long progressive disease and of unresponsiveness to any other treatment modality for thyroid cancer.

\section{Perspectives}

Since gene therapy was first used in 1990 for adenosine deaminase deficiency, more than 160 clinical genetherapy trials have been registered by the National Institutes of Health. So far, the actual success of gene therapy in terms of a benefit for the patients seems to be a little disappointing $(19,39)$. However, research in the field is rapidly going on. Projects focus on the development of more efficient targeting adjuvants, viral or nonviral, (19-21) and on modifying viral antigens to achieve more efficient infection or enhancing the specificity of the transduction of foreign genes by utilising tissue-specific promoters. The latter strategy has been followed also in the thyroid system $(36,37)$. Other perspectives come from the observation that combination therapies are more efficient than the treatment with one agent alone. In the context of thyroid cancers, this was tested for genetic immunotherapy (39), for suicide therapy (73), and also for radioimmunotherapy (74).

As for RA treatment, first results are encouraging to further investigate the potential of a redifferentiation therapy for thyroid cancer. It will have to be clarified what may be described as a therapeutic success in this context. For example, a decrease in the level of the tumour marker $\mathrm{Tg}$ in some patients is not an unambiguous finding. An increase might be interpreted on the one hand as resulting from further tumour growth, on the other hand as a consequence of differentiation leading to an enhanced synthesis and secretion of this thyroidspecific protein by thyrocytes not correctly organised in follicles. Tumour size would be the most valuable parameter, but is often difficult to determine, especially when diffuse metastases are involved. FDG-PET could play an important role for diagnosis in this context. Also, the right time point for RA therapy has to be determined. In in vitro studies, responsivity to RA decreased with progressive malignancy of thyroid carcinoma cells, as exemplified by the stimulation of type I $5^{\prime}$ deiodinase and NIS mRNA in follicular, but not anaplastic, lines $(63,66)$. Moreover, in patients, a remaining, but insufficient iodide uptake can be enhanced by RA treatment to therapeutically useful levels (72). These observations suggest that patients with less advanced tumours might respond better to RA redifferentiation, which should be considered in further studies. Another point is to decide whether a reduction in tumour growth is achieved by the action of the ${ }^{131} \mathrm{I}$ applied afterwards for diagnostic or therapeutic purposes after RA therapy or the consequence of the growth-inhibiting or pro-apoptotic effects of RA itself, as different modes of RA application to optimise the desired 
outcome might be required. In the latter case, the use of synthetic RA derivatives that display limited ranges of effects, for example, growth reduction by interaction with AP-1 (75) might be particularly potent. Finally, concepts of combination therapy may be considered also for thyroid carcinomas. For other cancers, a wide variety of compounds has been evaluated in combination with RA (61), above all interferon $\alpha$ in the case of solid tumours (76). The observation that in pilot studies a subgroup of patients definitely showed a positive response together with the well known fact that RA causes only comparatively mild and well tolerable side effects certainly warrants further investigation in this direction.

Altogether, there seem to be multiple options and a growing potential in the new approaches reviewed in this article, and it is conceivable that patients will soon have the benefit from their introduction into the therapeutic repertoire against thyroid cancer.

\section{Acknowledgements}

This work was supported by Deutsche Forschungsgemeinschaft (Wi231/9-2, 3), Wilhelm-SanderStiftung (\#95.069.1), and the Bavarian Government (Hochschulsonderprogramm III).

\section{References}

1 Braverman LE \& Utiger RD (eds) The Thyroid: a Fundamental and Clinical Text. Philadelphia: Lippincott-Raven, 1996.

2 Goretzki PE, Simon D, Frilling A, Witte J, Reiners C, Grussendorf M et al. Surgical reintervention for differentiated thyroid carcinoma. British Journal of Surgery 199480 1131-1134.

3 Filetti S, Bidart JM, Arturi F, Caillou B, Russo D \& Schlumberger M. Sodium/iodide symporter: a key transport system in thyroid cancer cell metabolism. European Journal of Endocrinology 1999 $141443-457$

4 Brabant G, Maenhaut C, Köhrle J, Scheumann G, Dralle H, Hoang-Vu C et al. Human thyrotropin receptor gene: expression in thyroid tumours and correlation to markers of thyroid differentiation and dedifferentiation. Molecular and Cellular Endocrinology 1991 82 R7-R12.

5 Shi Y, Zou M \& Farid NR. Expression of thyrotropin receptor gene in thyroid carcinoma is associated with a good prognosis. Clinical Endocrinology 199339 267-268.

6 Schlumberger MJ. Papillary and follicular thyroid carcinoma. New England Journal of Medicine 1998338 297-306.

7 Mazzaferri EL. An overview of the management of papillary and follicular thyroid carcinoma. Thyroid $19999421-427$.

8 Ain KB. Anaplastic thyroid carcinoma: behaviour, biology, and therapeutic approaches. Thyroid 19988 715-726.

9 Marsh DJ, Learoyd DL \& Robinson BG. Medullary thyroid carcinoma: recent advances and management update. Thyroid $19955407-424$.

10 Giuffrida D \& Gharib H. Current diagnosis and management of medullary thyroid carcinoma. Annals of Oncology 1998 9695-701.

11 Weinberg RA. How cancer arises. Scientific American 1996271 $62-75$.

12 Vogelstein B \& Kinzler KW. The multistep nature of cancer. Trends in Genetics 19934 138-141.

13 Dralle H, Gimm O, Simon D, Frank-Raue K, Görtz G, Niederle B et al. Prophylactic thyroidectomy in 75 children and adolescents with hereditary medullary thyroid carcinoma: German and Austrian experience. World Journal of Surgery $199822744-751$.

14 Rochefort P, Caillou B, Michiels F-M, Ledent C, Talbot M, Schlumberger $\mathrm{M}$ et al. Thyroid pathologies in transgenic mice expressing a human activated Ras gene driven by a thyroglobulin promoter. Oncogene $199612111-118$.

15 Burgess JR, Duffield A, Wilkinson SJ, Ware R, Greenaway TM, Percival J \& Hoffman L. Two families with an autosomal dominant inheritance pattern for papillary carcinoma of the thyroid. Journal of Clinical Endocrinology and Metabolism 199782 345-348.

16 Wynford-Thomas D. Molecular basis of epithelial tumorigenesis: the thyroid model. Critical Reviews in Oncogenesis $199341-23$.

17 Farid NR. Molecular pathogenesis of thyroid cancer: the significance of oncogenes, tumor suppressor genes, and genomic instability. Experimental and Clinical Endocrinology and Diabetes $19961041-12$.

18 Blaese RM. Gene therapy for cancer. Scientific American 1997276 111-115.

19 Gómez-Navarro J, Curiel DT \& Douglas JT. Gene therapy for cancer. European Journal of Cancer 199935 867-885.

20 Friedman T. Overcoming the obstacles to gene therapy. Scientific American 1997276 96-101.

21 Felgner PL. Nonviral strategies for gene therapy. Scientific American 1997276 102-106.

22 Weiner DB \& Kennedy RC. Genetic vaccines. Scientific American $199928150-70$.

23 Gallagher WM \& Brown R. p53-oriented cancer therapies: current progress. Annals in Oncology 199910 139-150.

24 Fagin JA, Matsuo K, Karmakar A, Chen DL, Tang SH \& Koeffler HP. High prevalence of mutations of the p53 gene in poorly differentiated human thyroid carcinomas. Journal of Clinical Investigation 199391 179-184.

25 Salvatore D, Celetti A, Fabien N, Paulin C, Martelli ML, Battaglia C, Califano D, Monaco C, Viglietto G, Santoro M \& Fusco A. Low frequency of p 53 mutations in human thyroid tumours; p53 and Ras mutation in two out of fifty-six thyroid tumours. European Journal of Endocrinology 1996134 177-183.

26 Battista S, Martelli ML, Fedele M, Chiappetta G, Trapasso F, De Vita $\mathrm{G}$ et al. A mutated p53 gene alters thyroid cell differentiation. Oncogene 199511 2029-2037.

27 Fagin JA, Tang SH, Zeki K, Di Lauro R, Fusco A \& Gonsky R. Reexpression of thyroid peroxidase in a derivative of an undifferentiated thyroid carcinoma cell line by introduction of wild-type p53. Cancer Research 199656 765-771.

28 Moretti F, Farsetti A, Soddu S, Misiti S, Crescenzi M, Filetti S et al. p53 re-expression inhibits proliferation and restores differentiation of human thyroid anaplastic carcinoma cells. Oncogene 1997 $14729-740$.

29 Velasco JA, Medina DL, Romero J, Mato ME \& Santisteban P. Introduction of p53 induces cell-cycle arrest in p53-deficient human medullary-thyroid-carcinoma cells. International Journal of Cancer 199773 449-455.

30 Zeki K, Tanaka Y, Morimoto I, Kimura A, Yamashita U \& Eto S. Induction of expression of MHC-class-II antigen on human thyroid carcinoma by wild-type p53. International Journal of Cancer $199875391-395$.

31 Narimatsu M, Nagayama Y, Akino K, Yasuda M, Yamamoto T, Yang T-T et al. Therapeutic usefulness of wild-type p53 gene introduction in a p53-null anaplastic thyroid carcinoma cell line. Journal of Clinical Endocrinology and Metabolism 199883 3668-3672.

32 Blagosklonny MV, Giannakokou P, Wojtowicz M, Romanova LY, Ain KB, Bates SE et al. Effects of p53-expressing adenovirus on the chemosensitivity and differentiation of anaplastic thyroid cancer cells. Journal of Clinical Endocrinology and Metabolism 199883 2516-2522.

33 Moolten FL \& Wells JM. Curability of tumours bearing herpes thymidine kinase genes transferred by retroviral vectors. Journal of the National Cancer Institute 199082 297-300.

34 Nishihara E, Nagayama Y, Narimatsu M, Namba H, Watanabe M, Niwa et al. Treatment of thyroid carcinoma cells with four 
different suicide gene/prodrug combinations in vitro. Anticancer Research $1998181521-1525$.

35 Nishihara E, Nagayama Y, Mawatari F, Tanaka K, Namba H, Niwa M et al. Retrovirus-mediated herpes simplex virus thymidine kinase gene transduction renders human thyroid carcinoma cell lines sensitive to ganciclovir and radiation in vitro and in vivo. Endocrinology 1997138 4577-4583.

36 Braiden V, Nagayama Y, Iitaka M, Namba H, Niwa M \& Yamashita S. Retrovirus-mediated suicide gene/prodrug therapy targeting thyroid carcinoma using a thyroid-specific promoter. Endocrinology 1998139 3996-3999.

37 Nagayama Y, Nishihara E, Iitaka M, Namba H, Yamashita S \& Niwa M. Enhanced efficacy of transcriptionally targeted suicide gene/prodrug therapy for thyroid carcinoma with the Cre-loxP system. Cancer Research 199959 3049-3052.

38 Missero C, Cobellis G, DeFelice M \& DiLauro R. Molecular events involved in differentiation of thyroid follicular cells. Molecular and Cellular Endocrinology $199814037-43$.

39 Nanni P, Forni G \& Lollini P-L. Cytokine gene therapy: hopes and pitfalls. Annals of Oncology $199910261-266$.

40 Zhang R, Minemura K \& DeGroot LJ. Immunotherapy for medullary thyroid carcinoma by a replication-defective adenovirus transducing murine Interleukin-2. Endocrinology $1998139601-608$.

41 Zhang R, Baunoch D \& DeGroot LJ. Genetic immunotherapy for medullary thyroid carcinoma: destruction of tumours in mice by in vivo delivery of adenoviral vector transducing the murine interleukin-2 gene. Thyroid 19988 1137-1145.

42 Zhang R, Straus FH \& DeGroot LJ. Effective genetic therapy of established medullary thyroid carcinomas with murine interleukin2: dissemination and cytotoxicity studies in a rat tumor model. Endocrinology 1999140 2152-2158.

43 Shimura H, Haraguchi K, Miyazaki A, Endo T \& Onaya T. Iodide uptake and experimental 131-I therapy in transplanted undifferentiated thyroid cancer cells expressing the Na+/I-symporter gene. Endocrinology $19971384493-4496$.

44 Turk E \& Wright EM. Membrane topology motifs in the SGLT cotransporter family. Journal of Membrane Biology 1997159 1-20.

45 Schmutzler C \& Köhrle J. Implications of the molecular characterization of the sodium-iodide symporter (NIS). Experimental and Clinical Endocrinology and Diabetes 1998106 S1S10.

46 Mandell RB, Mandell LZ \& Link CJ Jr. Radioisotope concentrator gene therapy using the sodium/iodide symporter gene. Cancer Research $199959661-668$.

47 Spitzweg C, Zhang S, Bergert ER, Castro MR, McIver B, Heufelder AE et al. Prostate-specific antigen (PSA) promoter-driven androgeninducible expression of sodium iodide symporter in prostate cancer cell lines. Cancer Research 199959 2136-2141.

48 Venkataraman GM, Yatin M, Marcinek R \& Ain KB. Restoration of iodide uptake in dedifferentiated thyroid carcinoma: relationship to human $\mathrm{Na}^{+} / \mathrm{I}^{-}$symporter gene methylation status. Journal of Clinical Endocrinology and Metabolism 199984 2449-2457.

49 Kowalczyk DW \& Ertl HC. Immune responses to DNA vaccines. Cellular and Molecular Life Sciences 199955 751-770.

50 Haupt K, Siegel F, Lu M, Saller B, Yang D, Mann K et al. Induction of a cellular and humoral immune response against the tumor associated antigen calcitonin by genetic immunization. Journal of Endocrinological Investigation 199922 (Suppl) 4 (abstract).

51 Maenhaut C, Roger P, Reuse S \& Dumont JE. Activation of the cyclic AMP cascade as an oncogenic mechanism: the thyroid example. Biochimie 199173 29-36.

52 Cerutti J, Trapasso F, Battaglia C, Zhang L, Martelli ML, Visconti R et al. Block of c-myc expression by antisense oligonucleotides inhibits proliferation of human thyroid carcinoma cell lines. Clinical Cancer Research 19962 119-126.

53 Juweid ME, Hajjar G, Swayne LC, Sharkey RM, Suleiman S, Herskovic T et al. Phase I/II trial of (131)I-MN-14F(ab)2 anticarcinoembryonic antigen monoclonal antibody in the treatment of patients with metastatic medullary thyroid carcinoma. Cancer $1999851828-1842$.
54 Kastner P, Mark M \& Chambon P. Nonsteroid nuclear receptors: what are genetic studies telling us about their role in real life? Cell $199583859-869$.

55 Hofman C \& Eichele G. Retinoids in development. In The Retinoids: Biology, Chemistry and Medicine, pp 597-630. Eds MB Sporn, AB Roberts \& DS Goodman. New York: Raven, 1994.

56 Maden M, Gale E \& Zile M. The role of vitamin A in the development of the central nervous system. Journal of Nutrition $1998128471 \mathrm{~S}-475 \mathrm{~S}$.

57 Langston AW, Thompson JR \& Gudas LJ. Retinoic acid-responsive enhancers located $3^{\prime}$ of the Hox A and Hox B homeobox gene clusters. Journal of Biological Chemistry 1997272 21672175.

58 Chytil F. Retinoids in lung development. FASEB Journal 199610 986-992.

59 Fisher GJ \& Voorhees JJ. Molecular mechanisms of retinoid actions in skin. FASEB Journal $1996101002-1013$.

60 Van Pelt AMM \& De Rooij DG Synchronization of the seminiferous epithelium after vitamin A replacement in vitamin-A-deficient mice. Biology of Reproduction 199043 363-367.

61 Chomienne C. Fenaux P \& Degos L. Retinoid differentiation therapy in promyelocytic leukemia. FASEB Journal 199610 1025-1030.

62 Hong WK \& Itri LM. Retinoids and human cancer. In The Retinoids: Biology, Chemistry and Medicine, pp. 597-630. Eds MB Sporn, AB Roberts \& DS Goodman. New York: Raven, 1994.

63 Schreck R, Schnieders F, Schmutzler C \& Köhrle J. Retinoids stimulate type I iodothyronine $5^{\prime}$-deiodinase activity in human follicular thyroid carcinoma cell lines. Journal of Clinical Endocrinology and Metabolism 199479 791-798.

64 Schmutzler C, Brtko J, Bienert K \& Kohrle J. Effects of retinoids and role of retinoic acid receptors in human thyroid carcinomas and cell lines derived therefrom. Experimental and Clinical Endocrinology Diabetes 1996104 16-19.

65 van Herle AJ, Agatep ML, Padua DN III, Totanes TL, Canlapan DV, van Herle HML et al. Effects of 13 cis-retinoic acid on growth and differentiation of human follicular carcinoma cells (UCLA RO 82 W-1) in vitro. Journal of Clinical Endocrinology and Metabolism 1990 $71755-763$.

66 Schmutzler C, Winzer R, Meissner-Weigl J \& Kohrle J. Retinoic acid increases sodium/iodide symporter mRNA levels in human thyroid cancer cell lines and suppresses expression of functional symporter in nontransformed FRTL-5 rat thyroid cells. Biochemical and Biophysical Research Communications $1997240832-$ 838 .

67 Bassi V, Vitale M, Feliciello A, De Riu S, Rossi G \& Fenzi G. Retinoic acid induces intercellular adhesion molecule-1 hyperexpression in human thyroid carcinoma cell lines. Journal of Clinical Endocrinology and Metabolism 199580 1129-1135.

68 Hoang-Vu C, Bull K, Schwarz I, Krause G, Schmutzler C, Aust G et al. Regulation of CD97 Protein in thyroid carcinoma. Journal of Clinical Endocrinology and Metabolism 199984 1104-1109.

69 Simon D, Köhrle J, Reiners C, Boerner A, Schmutzler C, Mainz K et al. Redifferentiation therapy with retinoids - a therapeutic option in advanced follicular and papillary thyroid carcinoma? World Journal of Surgery 199822 569-574.

70 Simon D, Köhrle J, Reiners C, Groth P, Börner AR, Grünwald Fet al. Redifferentiation therapy in thyroid cancer - results of a multicenter pilot study. International Symposium 'Thyroid Cancer: Pathogenesis, Diagnosis including PET, and Treatment', Linz, Austria, October 7-10 (1998). Thyroid 199881217.

71 Grünwald F, Pakos E, Bender H, Menzel C, Otte R, Palmedo et al. Redifferentiation therapy with retinoic acid in follicular thyroid cancer. Journal of Nuclear Medicine 199839 1555-1558.

72 Grünwald F, Menzel C, Bender H, Palmedo H, Otte R, Fimmers R et al. Redifferentiation therapy-induced radioiodine uptake in thyroid cancer. Journal of Nuclear Medicine $1998391903-$ 1906.

73 Soler MN, Milhaud G, Lekmine F, Treilhou-Lahille F, Klatzman D \& Lausson S. Treatment of medullary thyroid carcinoma by 
combined expression of suicide and interleukin-2 genes. Cancer Immunology Immunotherapy 199948 91-99.

74 Behr TM, Wulst E, Radetzky S, Blumenthal RD, Dunn RM, Gratz S et al. Improved treatment of medullary thyroid cancer in a nude mouse model by combined radioimmunochemotherapy: doxorubicin potentiates the therapeutic efficacy of radiolabeled antibodies in a radioresistant tumor type. Cancer Research 1997 57 5309-5319.

75 Zhou X-F, Shen X-Q \& Shemshedini L. Ligand-activated retinoic acid receptor inhibits AP-1 transactivation by disrupting c-jun/c-fos dimerization. Molecular Endocrinology 199913 $276-285$.

76 Lippman SM, Lotan R \& Schleuniger U. Retinoid-interferon therapy of solid tumours. International Journal of Cancer 199770 481-483.

Received 8 February 2000

Accepted 2 March 2000 